MATEC Web of Conferences 6, 07002 (2013)

DOI: $10.1051 /$ matecconf/20130607002

(C) Owned by the authors, published by EDP Sciences, 2013

\title{
Characteristics of mechanical and rheological properties of concrete under heating conditions up to $200^{\circ} \mathrm{C}$
}

\author{
V. Korsun, A. Korsun and A. Volkov \\ Donbas National Academy of Civil Engineering and Architecture, Makeyevka, Ukraine
}

\begin{abstract}
The results of experimental research of high up to $200{ }^{\circ} \mathrm{C}$ temperature influence and scale effect on temperature and shrinkage strain, creep and characteristics of strength and strain properties of high-strength modified fine and heavy concretes under axial compression are presented in the article. The practical way of accounting of the influence of the scale effect on design variables of shrinkage strain and concrete creep is proposed.
\end{abstract}

\section{INTRODUCTION}

Modified concretes based on organic-modifiers characterized by high (55-80 MPa) and ultra-high (over $80 \mathrm{MPa}$ ) strength, low permeability, high corrosion resistance and durability have become widespread in the building sphere $[1,2]$. The use of high-strength concrete in construction under the influence of higher technological temperatures seems to be perspective. However, the changes of physical-mechanical and rheological properties of concrete exposed to heating are insufficiently studied.

\section{CONCRETE MIX PROPORTION, TEST SPECIMENS SIZES AND TEST PROCEDURE}

The main objects of study are specimens made of heavy and fine high-strength concretes with organicmineral modifiers [1] containing silica fume, fly ash of Donetsk region thermal power-stations, fluidifier and concrete hardening controller. Concrete mixes: heavy concrete with crushed granite (concrete mix $\left.\mathcal{N}^{\circ} 1\right)$ - Cement: Sand: Crushed Stone $=1: 1.1: 2.2$ with $W / C=0.3$ with a modifier in the amount of $20 \%$ of cement weight $($ slump $=21 \mathrm{~cm})$, fine concrete $\left(\right.$ concrete mix $\left.\mathcal{N}^{\circ} 2\right)-$ Cement: Sand $=1: 1.8$ with $W / C=0.26$ with a modifier in the amount of $10 \%$ of cement weight (slump $=25 \mathrm{~cm}$ ). Silica sand with the fineness modulus of 1.9 is used for fine concretes. Basic specimens in standard sizes are cubes with the edge of $150 \mathrm{~mm}$ and prisms with dimensions of $150 \times 150 \times 600 \mathrm{~mm}$. Additional specimens are cubes with the edge of $100 \mathrm{~mm}$ and prisms with dimensions of $100 \times 100 \times 400 \mathrm{~mm}$, $250 \times 250 \times 650 \mathrm{~mm}$ and $300 \times 300 \times 800 \mathrm{~mm}$.

When heating the specimens the thermal response was equal to $15^{\circ} \mathrm{C}$ per hour, the first short duration of heating before pressure testing at temperatures of 90,150 and $200{ }^{\circ} \mathrm{C}$ was 15,13 and 12 hours respectively which corresponds to the time of conventional heavy concrete reaching the minimum strength under similar testing temperature conditions [3]. The length of durable heating at the temperatures tested was respectively 40,30 and 20 days. The loading of all samples was carried out under the press capacity of $2500 \mathrm{kN}$ with block step magnitude of 0.1 of the tolerated stress with a 5 -minute interval at each block step. The characteristics of concrete deformation properties, the tangent modulus of elasticity $E_{c}$ and the Poisson's ratio $v$, were determined according to the standard method at the level of loading $\eta=\sigma_{c} / f_{c} \leq 0.3$, the shortening strain $\varepsilon_{c u_{1}}$ and extensional strain $\varepsilon_{c u_{2}} \approx \varepsilon_{c u_{3}}-$ according to the values corresponding to the maximum level of stress achieved in the experiments.

This is an Open Access article distributed under the terms of the Creative Commons Attribution License 2.0, which permits unrestricted use, distribution, and reproduction in any medium, provided the original work is properly cited. 


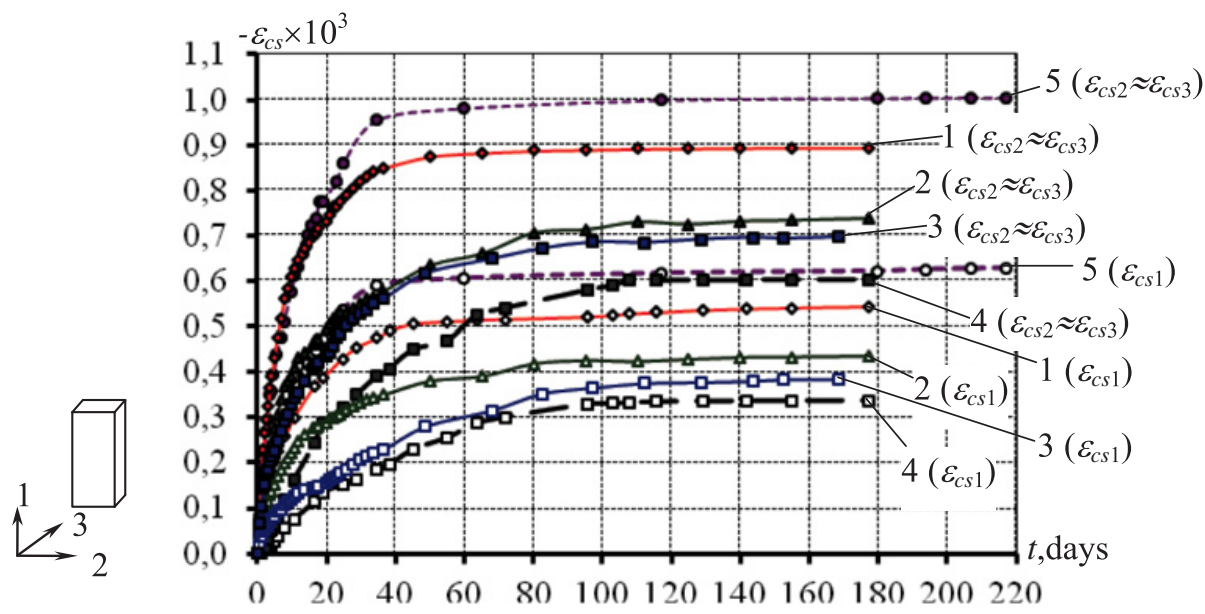

Figure 1. The relative shrinkage strain of prism specimens of high-modified concrete of different sizes at normal temperature: $1,2,3,4-$ granite concrete specimens (concrete $\mathcal{N}^{\circ} 1$ ) with dimensions $100 \times 100 \times 400 \mathrm{~mm}$; $150 \times 150 \times 600 \mathrm{~mm}, 250 \times 250 \times 650 \mathrm{~mm}, 300 \times 300 \times 800 \mathrm{~mm}$ respectively; 5 - fine concrete specimens with dimensions $100 \times 100 \times 400 \mathrm{~mm}\left(\right.$ concrete $\left.\operatorname{mix} \mathcal{N}^{\circ} 2\right)$.

\section{THERMAL AND SHRINKING DEFORMATIONS OF CONCRETE}

The experimental results indicate a significant dependence of temperature-shrinkage deformation, characteristics of strength and deformation properties of high strength concrete on the size of test specimens, temperature and heating duration (Fig. 1, Fig. 2).

In conditions of normal temperature the deformation shrinkage of high-strength concrete $\mathcal{N}^{\mathrm{o}} 1$ in the longitudinal direction of the specimens $150 \times 150 \times 600 \mathrm{~mm}$ in size made in average $43.5 \cdot 10^{-5}$ while the specimens $100 \times 100 \times 400 \mathrm{~mm}$ and $250 \times 250 \times 650 \mathrm{~mm}$ in size $-125 \%$ and $88 \%$ respectively of the values of reference prisms (Fig. 1). Fine concrete shrinkage strain of concrete $\mathcal{N}^{\circ} 2$ was on average $14 \%$ higher than that of concrete $\mathcal{N}^{\circ} 1$. The shrinkage deformation for the test specimens of all sizes in the transverse direction was 1.6-1.8 times higher than the corresponding values in the longitudinal direction.

During the first short-term heating up to 90,150 and $200^{\circ} \mathrm{C}$ relative thermal extensional strains (Fig. 2) of modified heavy concrete prism specimens $150 \times 150 \times 600 \mathrm{~mm}$ in size made respectively $82 \times 10^{-5}, 128.9 \times 10^{-5}$ and $166 \times 10^{-5}$, during the prolonged heating $-43.8 \times 10^{-5}, 93.9 \times 10^{-5}$ and $129.2 \times 10^{-5}$. Full thermal shortening strains in a cooled after prolonged heating state according to heating temperatures mentioned made relatively $13.6 \times 10^{-5}, 11.0 \times 10^{-5}$ and $6.5 \times 10^{-5}$. The relative shrinkage strain during a long period of isothermal heating at temperatures of 90,150 and $200{ }^{\circ} \mathrm{C}$ were respectively $38.2 \times 10^{-5}, 35.0 \times 10^{-5}$ and $36.8 \times 10^{-5}$.

The average values of the linear thermal strain coefficient $\alpha_{b t}$ for the modified concrete in the temperature range of $20-200{ }^{\circ} \mathrm{C}$ during the first short-term heating made $\alpha_{b t}=10.3 \times 10^{-6}\left[{ }^{\circ} \mathrm{C}^{-1}\right]$, in the process of cooling after prolonged heating $-\alpha_{b t}=8.0 \times 10^{-6}\left[{ }^{\circ} \mathrm{C}^{-1}\right]$.

The characteristic data mentioned were numerically close to the corresponding values for the normal-weight concrete of medium strength [4].

The correlation between the relative limiting values of high-strength concrete shrinkage deformations and the open surface modulus $M_{0}$ of specimens is shown on Fig. 3. For practical purposes this correlation can be expressed by the relation:

$$
\varepsilon_{c s, u}\left(M_{0}\right)=\varepsilon_{c s, u} \cdot \gamma_{c s}\left(M_{0}\right)
$$




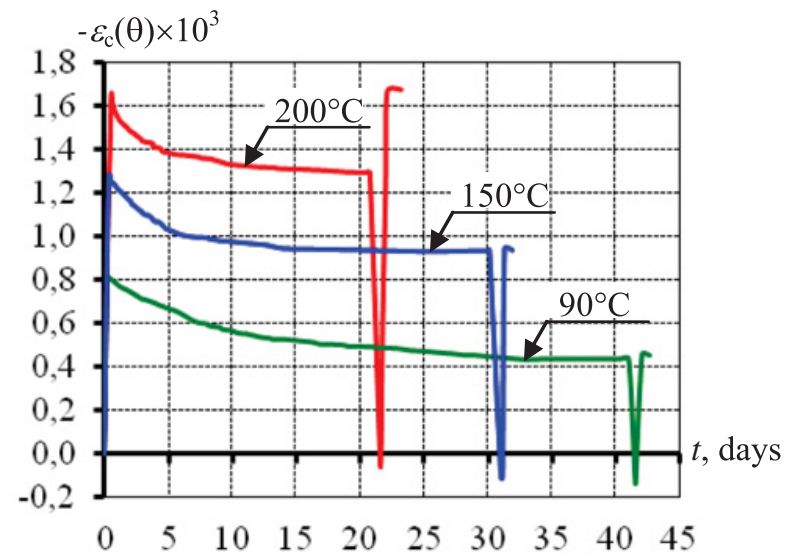

Figure 2. Temperature and shrinkage strains of high-strength heavy modified concrete $\mathcal{N}^{\circ} 1$ under heating up to $200{ }^{\circ} \mathrm{C}$.

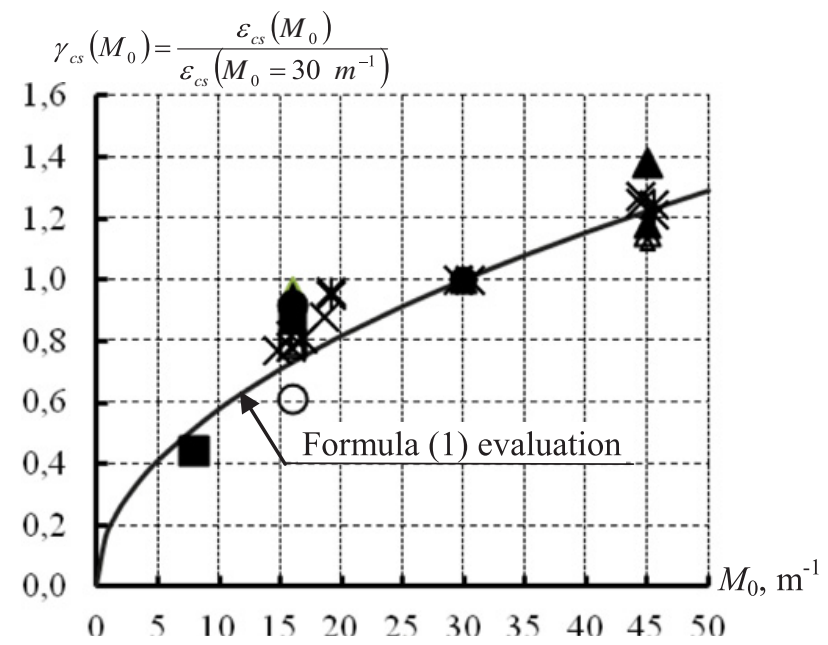

Figure 3. The dependence of the shrinkage strain relative limiting values of the high-strength concrete on the open surface modulus: $\Delta, \bigcirc, \square, \diamond, \times-$ the relative shrinkage values in the longitudinal direction of isolated and uninsulated specimens with dimensions of the cross-sectional surface of $100 \mathrm{~mm}, 150 \mathrm{~mm}$ and $250 \mathrm{~mm} ; \boldsymbol{\Lambda}$,

$\checkmark, *-$ the same as in transverse direction.

where

$\varepsilon_{n s, u}$ - the relative maximum value of deformation shrinkage of concrete specimens $150 \times 150 \times$ $600 \mathrm{~mm}$ in size with $M_{0}=30 \mathrm{~m}^{-1}$

$\gamma_{c s}\left(M_{0}\right)$ - the function of the specimens massiveness effect accounting on their shrinkage strains in comparison with the strains of reference specimens with $M_{0}=30 \mathrm{~m}^{-1}$ :

$$
\gamma_{s}\left(M_{0}\right)=\left(\frac{M_{0}}{30}\right)^{\frac{1}{2}} .
$$


A)

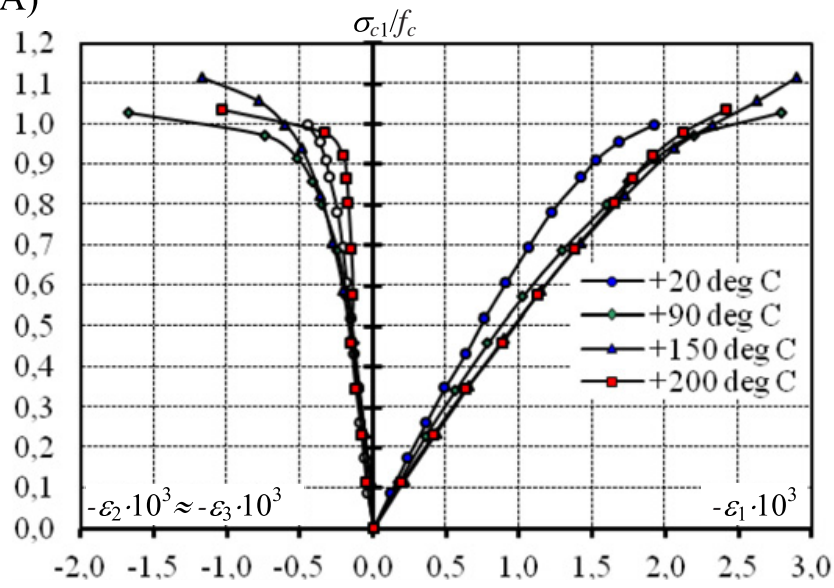

B)

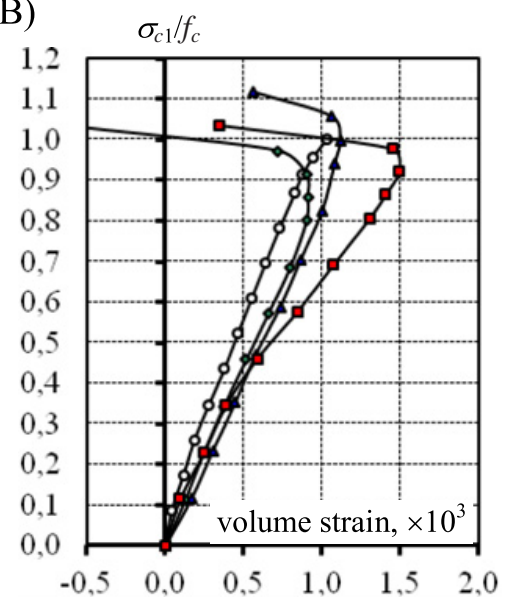

Figure 4. The effect of short-term heating on deformation curves of high-strain modified concrete under axial compression: A - linear strains; B - relative volume change.

\section{THE STRENGTH AND STRAIN OF CONCRETE UNDER SHORT-TERM AXIAL COMPRESSION}

Short-term heating of the concrete $\mathcal{N}^{\circ} 1$ up to a temperatures of 90,150 and $200{ }^{\circ} \mathrm{C}$ has led to the prism strength reduction by $10 \%, 3 \%$ and $4 \%$, the tangent modulus of elasticity - by $21 \%, 27 \%$ and $52 \%$, to the ultimate compressibility increase - by $9 \%, 17 \%$ and $34 \%$ compared with the corresponding characteristics at normal temperature (Fig. 4). Long-term heating in comparison with the short-term one at the same temperature results in partial restoration of concrete strength to the levels of $0.95,1.05$ and 0.98 of the unheated concrete strength as well as in reduction of the tangent modulus of elasticity by $25 \%, 37 \%$ and $42 \%$ and in increase of the ultimate compressibility by $21 \%, 38 \%$ and $45 \%$ compared with the corresponding characteristic values before heating.

Short-term heating of the fine modified concrete $\mathcal{N}^{\circ} 2$ up to temperatures 90,150 and $200{ }^{\circ} \mathrm{C}$ does not practically lead to the strength reduction, but causes decrease of the tangent modulus of elasticity by $20 \%, 28 \%$ and $33 \%$ and increase in ultimate compressibility by $18 \%, 24 \%$ and $27 \%$ compared with the concrete characteristics before heating.

Deformation curves of high-strength concrete under axial compression under the temperature range from 20 to $200{ }^{\circ} \mathrm{C}$ are shown on Fig. 4 .

Loading levels corresponding to the elastic deformation amounted for the modified high-strength concrete $\eta=0.7-0.8$. The process of the specimens elastic volume reduction changed into its increase (manifestation of the dilation effect) at loading levels over $\eta=0.8$.

The values of the Poisson's ratios $v$ of modified concrete with a crushed stone during shortterm heating up to 90,150 and $200{ }^{\circ} \mathrm{C}$ reduce by $17 \%, 28 \%$ and $42 \%$ respectively and do not significantly depend on heating duration. The same characteristics of fine concrete under the same heating temperature reduce by $17 \%, 34 \%$ and $38 \%$.

The changes in strength and strain properties of concretes exposed to elevated temperatures are caused by the manifestation of destructive and constructive factors in the concrete structure. The most significant destructive factors are structural stresses in the contact zone "matrix-aggregate" which in most cases become evident during the first heating of fine concretes. 
$\underline{\mathrm{A})}$

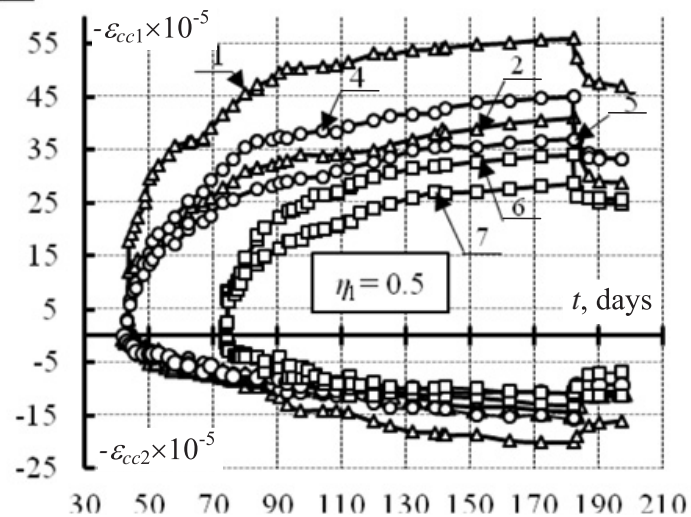

$\underline{\mathrm{B})}$

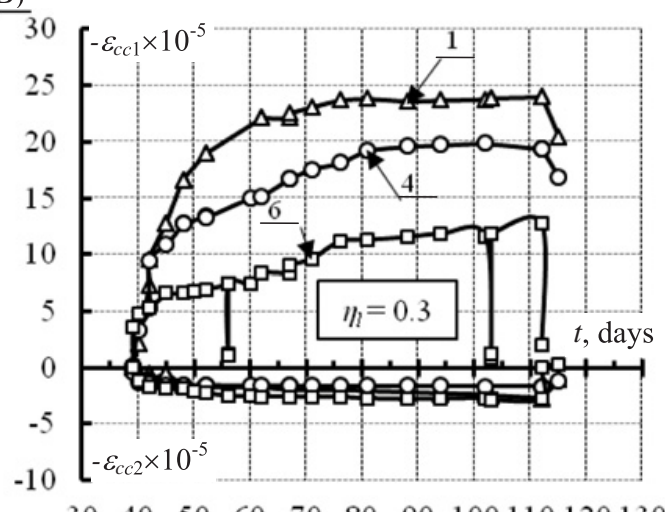

Figure 5. Longitudinal and transverse linear creep strains of concrete prisms at $20^{\circ} \mathrm{C}$ and loading levels $\eta_{l}=0.5$ (A) and $\eta_{l}=0.3$ (B): 1, 4, 6 - non-moistureproof prism specimens with cross-sectional dimensions $100 \mathrm{~mm}$, $150 \mathrm{~mm}, 250 \mathrm{~mm}$ and the open surface modulus values respectively $I_{0}=45,30,19 \mathrm{~m}^{-1} ; 2,5,7-$ the same as with partly moisterproof prisms respectively $M_{0}=16,16,8 \mathrm{~m}^{-1}$.

A)

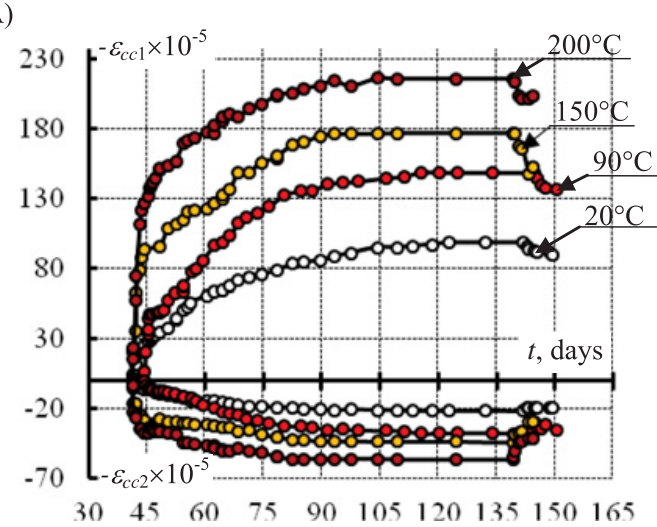

B)

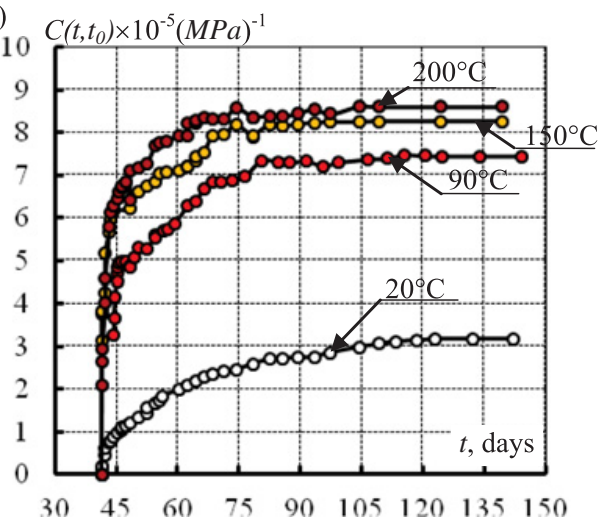

C)

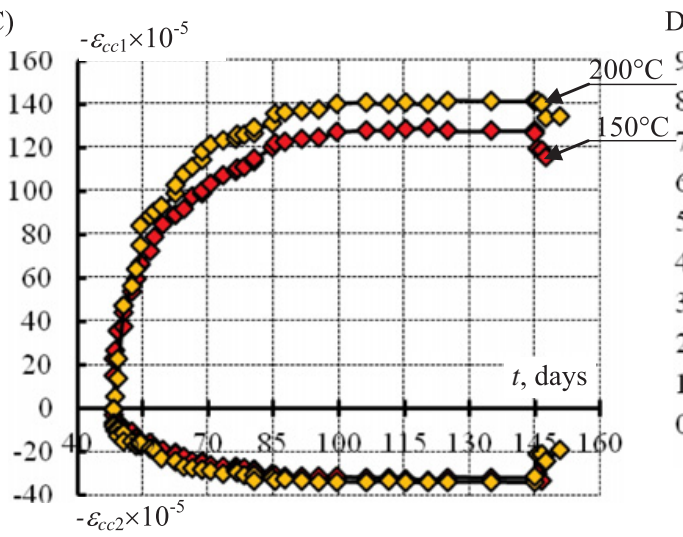

D) $C\left(t, t_{0}\right) \times 10^{-5}(M P a)^{-1}$

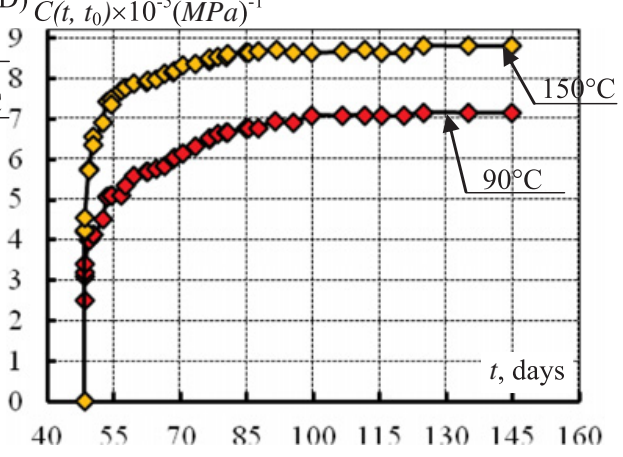

Figure 6. Influence of increased temperatures on the change of linear $\varepsilon_{c c}(\mathrm{~A}, \mathrm{C})$ and unit $C\left(t, t_{0}\right)(\mathrm{B}, \mathrm{D})$ creep strains of concrete at the loading level $\eta_{l}=0.5: \mathrm{A}, \mathrm{B}-$ for the prism specimens with the dimensions $150 \times 150 \times 600 \mathrm{~mm}$ $\left(M_{0}=30 \mathrm{~m}^{-1}\right) ; \mathrm{C}, \mathrm{D}-$ for the prism specimens with the dimensions $250 \times 250 \times 650 \mathrm{~mm}\left(M_{0}=19 \mathrm{~m}^{-1}\right)$. 


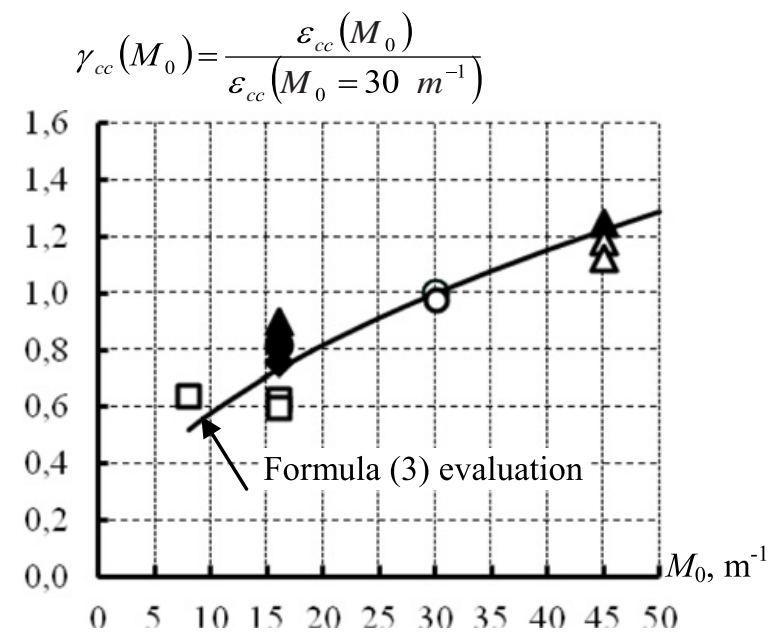

Figure 7. The dependence of the limiting creep values of concrete on the open surface modulus at normal temperature: $\triangle, O, \square$ - relative creep strains under long-term loading level $\eta_{l}=0.3 ; \boldsymbol{\Delta}, \boldsymbol{\bullet}, \mathbf{\square}-$ the same as under long-term loading level $\eta_{l}=0.5$.

\section{THE CREEP OF CONCRETE}

In normal temperature conditions the limiting values of the longitudinal creep strain for nonmoistureproof concrete prisms with dimensions of lateral sides $100 \mathrm{~mm}, 150 \mathrm{~mm}$ and $250 \mathrm{~mm}$, and the open surface modulus values respectively $M_{0}=45 \mathrm{~m}^{-1}, M_{0}=30 \mathrm{~m}^{-1}$ and $M_{0}=19 \mathrm{~m}^{-1}$ at the level of long-term loading $\eta_{l}=\sigma_{l} / f_{c}=0.3$ made $\varepsilon_{c c_{1}}=21.6 \cdot 10^{-5}, \varepsilon_{c c_{1}}=19.2 \cdot 10^{-5}$ and $\varepsilon_{c c_{1}}=12.2 \cdot 10^{-5}$, and at the level of long-term loading $\eta_{l}=0.5$ equal to $\varepsilon_{c c_{1}}=54.8 \cdot 10^{-5}, \varepsilon_{c c_{1}}=42.9 \cdot 10^{-5}$ and $\varepsilon_{c c_{1}}=32.1 \cdot 10^{-5}$ respectively.

For concrete specimens with the level of long-term compression $\eta_{l}=0.5$ and dimentions $150 \times$ $150 \times 600 \mathrm{~mm}\left(M_{0}=30 \mathrm{~m}^{-1}\right)$ the mean limit values of relative linear creep strain of concrete at temperatures of $20,90,150$ and $200^{\circ} \mathrm{C}$ were respectively $90.6 \times 10^{-5}, 150.1 \times 10^{-5}, 161.4 \times 10^{-5}$ and $216.5 \times 10^{-5}$. For specimens with dimensions $250 \times 250 \times 650 \mathrm{~mm}\left(M_{0}=19 \mathrm{~m}^{-1}\right)$, the mean limit values of the linear creep strain of concrete at heating temperatures up to 90 and $150^{\circ} \mathrm{C}$ made correspondingly $129 \times 10^{-5}$ and $141.4 \times 10^{-5}$ that is by $14.2 \%$ and $14.4 \%$ lower than for specimens of basic size. Reversible creep strain of concrete after complete unloading of basic specimens under the same temperature tests were respectively $9.3 \times 10^{-5}, 12.9 \times 10^{-5}, 15 \times 10^{-5}$ and $15.8 \times 10^{-5}$ (Fig. 5 $\mathrm{A}, \mathrm{B})$, and for specimens with dimensions $250 \times 250 \times 650 \mathrm{~mm}$, after heating at temperatures of 90 and $150^{\circ} \mathrm{C}$ were $10 \times 10^{-5}$ and $11.5 \times 10^{-5}$ respectively (Fig. $5 \mathrm{C}, \mathrm{D}$ ).

For specimens with dimensions $100 \times 100 \times 400 \mathrm{~mm}, 150 \times 150 \times 600 \mathrm{~mm}, 250 \times 250 \times 650 \mathrm{~mm}$ and partially moistureproof corner surfaces with the open surface modulus values respectively $M_{0}=16$, 16 and $8 \mathrm{~m}^{-1}$ the limit creep strain at the level of loading $\eta_{l}=0.5$ made respectively $\varepsilon_{c c_{1}}=38.9 \cdot 10^{-5}$, $\varepsilon_{c c_{1}}=35.6 \cdot 10^{-5}$ and $\varepsilon_{c c_{1}}=32.1 \cdot 10^{-5}$. Thus, for linear relative creep strain there is a tendency for the increase of their limit values with the open surface modulus of concrete $M_{0}$. The values of the specific creep strain $\left(t, t_{0}\right)=\varepsilon_{c c_{1}} / \sigma_{1}$ obtained from the results of experimental studies for the specimens of the same size at the level of loading $\eta_{l}=0.3$ made respectively $3.3 \cdot 10^{-5}, 2.6 \cdot 10^{-5}$ and $2.3 \cdot 10^{-5}$, at a level $\eta_{l}=0.5-4.3 \cdot 10^{-5}, 4.1 \cdot 10^{-5}$ and $3.7 \cdot 10^{-5}$, and for partially moistureproof specimens $\left(M_{0}=16,16\right.$ and $\left.8 \mathrm{~m}^{-1}\right)-3.7 \cdot 10^{-5}, 3.7 \cdot 10^{-5}$ and $3.3 \cdot 10^{-5}$ respectively. The values of linear $\varepsilon_{O c}$ and limit $C\left(t, t_{0}\right)$ creep strain with the same open surface modulus but with different cross-sectional dimensions are similar in their absolute values (Fig. 7). 
IWCS 2013
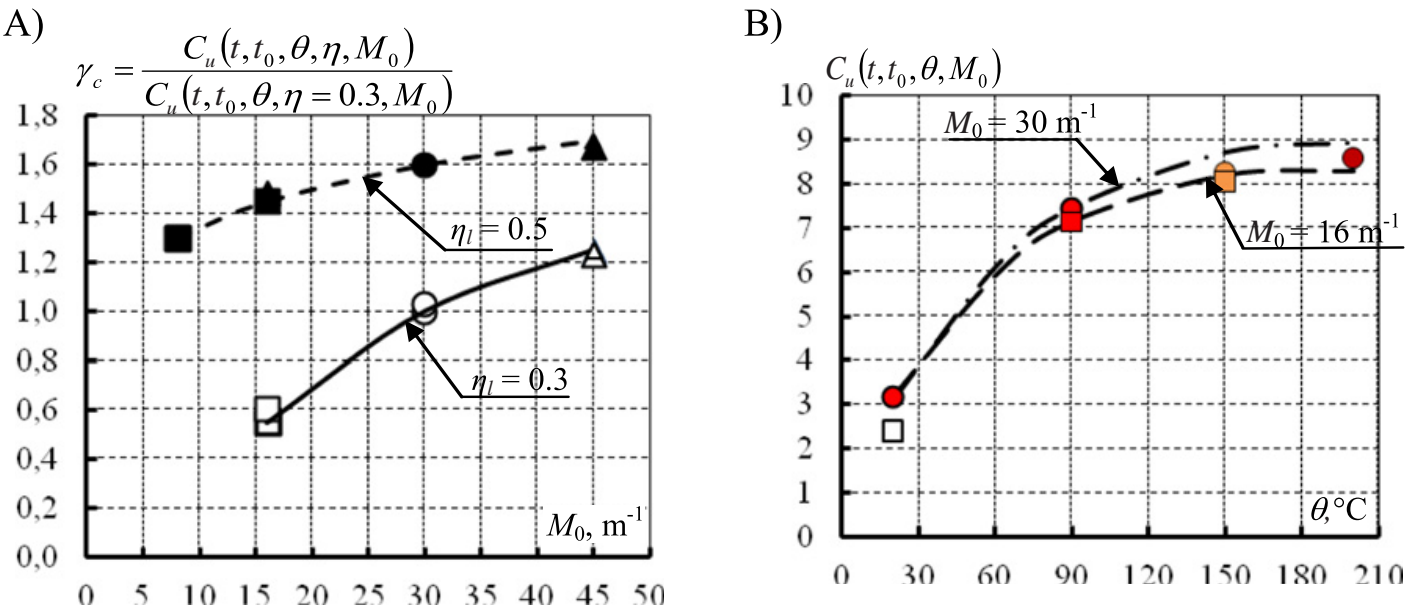

Figure 8. The influence of open surface modulus $M_{0}(\mathrm{~A})$ and heating temperature (B) on the specific limit values of the unit creep strain of concrete $\mathcal{N}^{\circ} 1$.

The research results show a higher growth rate of creep strain at high temperatures in the initial period after the application of load and non-linearity of the relationship between stress and the corresponding specific creep strain is shown more clearly than in normal conditions of temperature. Whereas the decay period of creep strain decreases with the increase of heating temperature (Figs. 5, 6).

The influence of size effect on the limit creep strain values of high-modified concrete (Fig. 7) $\varepsilon_{c c, u}\left(M_{0}\right)$ can be taken into account in practical calculations for the conditions of normal temperature with the function $\gamma_{c}\left(M_{0}\right)$ similar to (Eq. (1)):

$$
\varepsilon_{c c, u}\left(M_{0}\right)=\varepsilon_{c c, u} \cdot \gamma_{c}\left(M_{0}\right)
$$

where

$\varepsilon_{c c, u}$ - the maximum creep deformation of concrete specimens with the basic size $\left(M_{0}=30 \mathrm{~m}^{-1}\right)$ with the respective loading levels $\left(\eta_{l}\right)$;

$\gamma\left(M_{0}\right) \approx \gamma_{c s}\left(M_{0}\right)$.

\section{CONCLUSIONS}

6.1. The exact dependence of the strength, tangent modulus of elasticity, ultimate compressibility, creep and shrinkage deformation of concrete on specimens' dimension, temperature and duration of heating has been experimentally proved. With the increase of the open surface modulus $M_{0}$ of the specimens tested the limit values of the relative linear shrinkage and creep deformation of concrete increases. Linear creep specimens with the same open surface modulus $M_{0}$ but with different cross-sectional dimensions are close in absolute value. The open surface modulus $M_{0}$, defined by the ratio of open for drying surface to the volume of concrete in the structure can be accepted as a generalized characteristic that makes for accounting the size and conditions of concrete specimens drying (the scale effect).

6.2. The shrinkage deformations of high-strength concrete (concrete $\mathcal{N}^{\circ} 1$ ) at normal temperature in the longitudinal direction of the prism specimens $100 \times 100 \times 400 \mathrm{~mm}\left(M_{0}=45 \mathrm{~m}^{-1}\right), 150 \times$ $150 \times 600 \mathrm{~mm}\left(M_{0}=30 \mathrm{~m}^{-1}\right)$ and $250 \times 250 \times 650 \mathrm{~mm}\left(M_{0}=19 \mathrm{~m}^{-1}\right)$ in size are related in the ratio 1.25:1.0:0.88.

For prism specimens of all sizes shrinkage deformation in the transverse direction is by $1.6-1.8$ times higher than the corresponding values in the longitudinal direction due to different drying conditions of interior and exterior volumes of concrete in the structure. 


\section{MATEC Web of Conferences}

6.3. The impact of elevated temperatures in comparison with conventional high strength concretes has less influence on the strength of high-strength modified concretes (reduction is not more than 10\%) and a more significant impact on the performance of their deformation properties.

The long-term heating insignificantly changes the tangent modulus of concrete elasticity compared with the short-term heating, though it makes for the further increase of the ultimate compressibility compared with the corresponding characteristics of the concrete that is not exposed to heating.

The Poisson's ratio of concrete decreases proportionally to the temperature and heating and does not significantly depend on the duration of its action.

6.4. The irregularity of the strength and deformation properties of modified concretes in large-scale prism specimens is caused by different conditions of hardening and drying of internal and external volumes of concrete. Internal volumes of concrete require higher strength values $f_{c}$ (up to $25 \%$ ), the tangent modulus of elasticity $E_{c}$ (up to $16 \%$ ) and limit compressibility (12\%) compared with the values in external layers. Accounting for the mentioned irregularity of the properties in calculation allows to make the calculated values of strength and deformation structures closer to the tested ones and to use their bearing capacity reserves.

\section{References}

[1] Korsun A.V., Peculiarities of high-performance modified concrete deformation and destruction in the conditions of heating up to $+200^{\circ} \mathrm{C}$, Donbas National Academy of Civil Engineering and Architecture Journal, 2007-1(63), pp. 116-121, 2007 [in Russian with English Summary].

[2] Korsun A.V., Consideration of scale factor when defining mechanic properties characteristics of high-performance modified concrete, Luhansk National Agrarian University Research Journal, 14, pp. 86-91, 2010 [in Russian with English Summary].

[3] Korsun V.I., Stress-strain state of concrete structures in thermal actions, Donabas National Academy of Civil Engineering and Architecture, 153 pp., 2003 [in Russian] ISBN 966-7477-38-X.

[4] SNiP 2.03.04-84, Concrete and reinforced concrete structures designed to operate under elevated and high temperatures [in Russian], Moscow, 54 pp., 1985 [in Russian]. 